\title{
Farms as a resilience factors to land degradation in peri-urban areas
}

\author{
Paolo Zappavigna, Andrea Brugnoli \\ Department of Agricultural and Food Sciences (DISTAL), University of Bologna, Italy
}

\begin{abstract}
The purpose of this study was the analysis of the effects induced by urban pressures on the socio-economic and territorial characteristics of the rural peri-urban areas in order to identify planning and intervention strategies aimed at enhancing the quality of agriculture and landscape. A survey was conducted in the surroundings of Parma on farms located in the vicinity of urban areas. The structural, productive and social characteristics of the family-farm units were analyzed. The survey updated an identical survey, carried out in 1986, in which it was examined a sample of 208 farms. The units surveyed were evaluated in two aspects: the "vitality", which takes into account the structural characteristics (size, production, labour force, etc.), and the "stability", in which a crucial role is played by the age of the conductor and the presence of a successor. It was found that only $28 \%$ of the original farm sample is still alive, one third has disappeared, $30 \%$ was absorbed by existing farms, $8 \%$ has been abandoned. The factors most favourable to the survival resulted those referred to the vitality, especially the physical and economic size of the farm, the presence of cattle, the percentage of land in property, the presence of young labour. Among the factors that predispose to the abandonment, the urbanization processes were found to be determinants, in terms of expansion of both the built-up area and of that planned as urbanisable. The research has highlighted the importance of the vitality of the farms together with a context that has maintained its original rural features. These combined aspects can better define what we call the resiliency of the landfarms system i.e. the capability of positively reacting to the variable modifications of the internal and external conditions.
\end{abstract}

\section{Introduction}

The future of the landscape and environment characters of rural land is closely linked to the future of the productive primary structure

Correspondence: Paolo Zappavigna, Department of Agricultural and Food Sciences (DISTAL), University of Bologna, Viale G. Fanin 50, 40127 Bologna, Italy.

E-mail: paolo.zappavigna@unibo.it

Key words: rural areas, periurban, farms, planning.

(C) Copyright P. Zappavigna and A. Brugnoli., 2013

Licensee PAGEPress, Italy

Journal of Agricultural Engineering 2013; XLIV(s2):e164

doi:10.4081/jae.2013.s2.e164

This article is distributed under the terms of the Creative Commons Attribution Noncommercial License (by-nc 3.0) which permits any noncommercial use, distribution, and reproduction in any medium, provided the original author(s) and source are credited. that determined its identity over time. This is why the preservation of the agricultural space in its typical traits cannot be separated from the maintenance of a substrate of solid and viable farms, especially in areas with high urban pressure where the expectations of ground rent may overcome the much more modest profitability of enterprise.

Who looks with attention to the phenomena of transformation taking place in these areas, must recognize as the dynamic expansion of urban systems has given rise to a type of landscape with very heterogeneous and not uniquely defined characters, in which the signs of agricultural production mingle with the signs of urban activities causing an environmental scenario disarticulated and lacking its own identity. A landscape where intensive farming can coexist with industrial complexes, greenhouses sprout between the nuclei built, the wasteland mingle with emerging neighborhoods, fields tend to lose their attendance warping stripping trees, livestock contracts in few farms survivors.

This state of affairs suggests that a simple passive protection of land use, exclusively entrusted to restrictions of planning tools, is not sufficient to ensure over time the maintenance of landscape-environmental characteristics typical of the places and how the matter should be to leverage the inherent capacity of the agricultural production system to perform its own decisive function for an active protection of the territory. Which means to assign to agricultural enterprises a leading role, often unrecognized, of territorial processes.

\section{Materials and methods}

This view, which takes on the farms as co-protagonists of the destinies of the suburban areas, has inspired a research that we conducted in 2011 in Parma hinterland (municipalities of Parma, Collecchio and Sorbolo), as an update of a similar survey carried out in 1986 in the same context, in order to evaluate the effects of the dynamics of urbanization on primary production structure and the surrounding area.

In the first survey 208 farms had been examined by means of questionnaires administered to the conductor, located in different position with respect to the urban perimeter. Twenty-five years later, the survey has been repeated taking as object the same production units in order to ascertain the processes of adaptation/survival put in place by farms to be able to resist the urbanization pressure or, conversely, the degradation processes and the factors, structural or planning, which led to them.

In both surveys, the units surveyed were evaluated in two respects: "vitality" and "stability."

The vitality takes into account the structural characteristics and management activities and is parameterized according to certain thresholds of Standard Gross Margin (RLS), both overall and in relation to the total work units (ULT); stability concerns, on the one hand, the composition of family (with particular attention to the age of the farm manager and the presence of young people) and, on the other hand, the workforce, especially the family labour entity.

With regard to the vitality the following classes of farms have been 
defined: a) vital, when both RLS and RLS/ULT thresholds are exceeded; b) potentially vital but unprofitable when the only RLS absolute threshold is exceeded; c) profitable but not autonomous, when only the RLS/ULT threshold is exceeded; d) not vital, when none of the two thresholds is exceeded.

With regard to stability the following types of farms have been defined: stable, tended to be stable, potentially stable, tended to be unstable, unstable.

Combining the two indicators, vitality and stability, three classes of "value" have been identified, in order to obtain a ranking of "merit" for possible protection and support actions on the part of government policies in the area. So the farms have been grouped according to the scheme shown in the following Table 1 and defined as follows: deserving $(\mathrm{A})$, intermediate $(\mathrm{B})$, not deserving $(\mathrm{C})$.

\section{Results}

In previous research a dynamic transformation in the territory had been found aiming at the progressive loss of traditional agricultural connotations and the contraction/extensification of production, the more intense the closer to urban areas. However, it was also revealed the existence of a significant number of farms vital and quite stable able to respond to pressure from settlements with a strengthening of their production capacity. On the other hand an important role in order to stay on the farm of rural families was carried out by the strong bond with the land and the high value assigned to live in the country.

The general situation in which the farms are operating has changed however: both in terms of the of settlements growth, further increased and spread, and the conditions under which the production activity takes place (market trends, Common Agricultural Policy). But even more relevant has been, in this period, the continuation of the processes of productive extensification and aging of the workers, which were already established in the previous research The result was, as we shall see further, a significant impairment of the primary production tissue and, consequently, of the territorial scenario pertaining to it.

Without going into a detailed analysis of the results, which will be done in other places, we here briefly indicate the most significant.

The deterioration of the productive structure is evidenced by the following data: the disappearance due to urban expansion of a substantial proportion (about one third) of the units then surveyed, some of which had been regarded as vital; the downgrading of another $30 \%$ consisting of units absorbed by outer companies (mainly due to the advanced age of the owners); the decay of a further $8 \%$ of farms that are now managed without labour or simply abandoned.

Only $28 \%$ of the old sample is still present and active. A portion undoubtedly modest, but still potentially capable of maintaining even the connotation of rurality at least in some, more preserved, areas of peri-urban belt.

Table 1. Reference scheme for the attribution of the three value classes: $\mathrm{A}$ $=$ deserving; $\mathrm{B}=$ intermediate; $\mathrm{C}=$ not deserving.

\begin{tabular}{lccccc} 
& Stable & Tend. st. & Pot. st. Tend.un. Unst. \\
Vital & A & A & B & B & B \\
Pot. vital & A & B & B & C & C \\
\hline Prof.not aut. & B & B & C & C & C \\
Not vital & B & C & C & C & C \\
\hline
\end{tabular}

In fact, this sample, which appeared then mainly composed of vital and stable units, over time has become differentiating in two opposites addresses: a portion of farms where the aging process has led to a situation of high instability (manager and family very elderly); a portion, while smaller, of farms which have chosen the path of expanding the production capacity and income (also as a result of a fairly frequent replacement of families) reaching today an even higher level of vitality and stability. Such farms able to strengthen the policies for protecting the quality of landscape and environment are mainly located in the outer bands of the survey area, but there are some really interesting in the vicinity of the settled areas.

Among the factors that most influenced the evolution of the productive structure, urban sprawl is by far the one that led to the disappearance of most farms; on the other hand, the factor that has acted more favourably on permanence of survived farms was the, objective, structural consistency (size and profitability) of the farms, rather than the, subjective, composition of the family unit and its active involvement in agriculture (they are also companies which had in the past a low age of workers).

Among the new elements that have come to light, there was a phenomenon of the incorporation of many companies which were in the past autonomous in other companies, valid and vital, located in outer areas; an absorption process that we might consider of "farm relocation", which places these units in a limbo from which it will be difficult to come back to a new production autonomy. It is, however, a phenomenon that has not only negative aspects as it has enabled a significant enhancement of the "absorbent" farms. An ad hoc survey actually showed how these farms are equipped structurally and sociologically to a great vitality with a strong presence of youth. In these cases the divestiture has not resulted in the productive abandonment, but has indeed kept alive the agricultural activity and offered a possibility of strengthening and survival to other companies potentially better equipped and able to offer a more stable future to the adjacent territorial context.

There are however various signals that indicate how much of the surviving companies are in a situation which is still in transition, starting with the persistence of the aging processes and productive extensification (e.g. loss of cattle).

Of these signals, we can include also the novelty of some farms whose owners perform functions related to agriculture, but paying almost exclusively their work outside and then using the farm only as a home base for their activities (contractors, traders).

Turning our attention to the territory, the reading of the transformations of primary production, plus the analysis of the processes of urban sprawl and planning decisions taken in the period made it possible to highlight some important features in significant parts of the peri-urban space. In fact, some spatial sectors which remained not affected by the development of the city are clearly put into evidence, where the farm tissue and landscape are still quite intact.

These areas, mainly composed of four country wedges that penetrate so landlocked in the urban area, have proved to be strategic areas for a conversion of planning tools to take on the agricultural production as a factor structuring the decisions regarding the management of territory.

\section{Discussion}

Compared to the previous investigation, the research has brought to light some limitations of the classification adopted at the time, which was based on the capacity of the individual farming units to withstand external stresses, measured through an equal combination of vitality and stability indicators, as determined on the basis of the situation 
existing on the date of the survey.

Indeed, if we assume a vision of perspective, which looks at trends of medium to long term by trying to define (promote) desirable future scenarios, it must be recognized that the concept of "resistance" which briefly is the expression of the two indicators mentioned above presents limitations arising from the fact that the judgment on the merits, operated according to this principle, is based on an examination of the status quo referred to a given period. It has been seen that the evolutionary dynamics that have affected our farms in the past quarter-century have led to strong changes the original structure, in particular the family organization and farm management, often mainly for their intrinsic reasons, primarily the natural tendency to aging of household members; regardless of the external pressures.

On the other hand, the state of affairs in a given period is inevitably destined to change in time for the changing external conditions: market trends, agricultural and planning policies, technological and production innovation, social expectations etc..

A search that intends to foreshadow more sustainable future organization should therefore refer not so much to a current survival capacity corresponding to the conditions detected at a given time, as an ability "potential" to develop suitable alternative arrangements able to react positively to the possible amendments to the socio-economic and environmental scenario. Modifications which, in addition to family structure (including the possible exit of the managing family), may relate with the different public policies (planning, grants, etc..), the integrations with productive chains, the new opportunities offered by the multi-functionality, with particular reference to the urban proximity etc.

This observation has led us to reduce the importance given in the past to the criterion of farm stability (based, as we have said, on the family conditions and labour supply) because highly variable over time, and give greater weight, decisive for our purposes, to the criterion of viability, based mainly on longer-lasting structural characteristics.

This indicator, indeed, proved to be able to justify by itself the permanence of most farms survivors. It is demonstrated on the one hand by the fact that many of the surveyed farms are still fully functional even if run by families very old (in this, probably also thanks to the contribution of families co-inhabitants, a situation greatly increased in the period). On the other hand it is confirmed by a new phenomenon observed, i.e. taking charge of some divested farms by other more viable farms; phenomenon which, in addition to having propitiated an increasing efficiency of incorporating farms, has allowed to maintain unchanged the physical-environmental context of the absorbed ones. Even a phenomenon that can affect much on profitability, which is the significant reduction of the cattle husbandry (more than halved in the meantime), it was not enough, for the farms involved, to determine the abandonment of production.

Based on these considerations, we considered it more appropriate to replace the concept of resistance with the concept of "resilience" of the system farms-territory, meaning by this term the susceptibility of a given socio-economic and environmental organization to react positively to changes in external conditions, to grasp opportunities for development and innovation, to be able to create a new, more adaptable and durable structure: in both farming and territorial level.

On this basis, and on the basis of the findings of our research, we could distinguish, as useful for our purposes, two different levels of resilience: a farm level, which measures the ability to provide a positive response to the expected/possible changes according to objective and subjective (to a lesser extent) conditions existing in individual enterprises; a territorial level, in which the positive response to changes (i.e. consistent with a given project on the area) depends on the integrity and the favourable disposition of the spatial and environmental context.

The synergistic presence of both conditions, i.e. strength of the family-farm unit and integrity of the territory of belonging, can significant- ly increase the potential capacity of resilience of the system land-farms.

A situation of this type has been highlighted by our research which has put into evidence important portions of the territory where the absence of expansionary actions of the city, the preserved integrity of land organization and the presence of a farm tissue alive and vital have positively contributed to the maintenance of the original connotation of rurality and of its landscape-environmental values. These areas may, in our opinion, be considered as primary for the protection and support on the part of government policies.

\section{Conclusions}

The considerations made suggest an original method to select the areas of intervention of territorial policies and offer guidance to develop the most appropriate strategies.

Beside the structural and social endowment of individual farms become also important, on a larger scale, some factors (structural and locational) that can make farms, situated in areas subject to external pressure, vital and profitable. For example, greater importance is assumed by: a) the size of the farm rather than the presence of animal husbandry; b) the localization in the context of particular attractiveness and/or accessibility for the urban population; c) the ability to offer products to the consumer citizens (zero km); d) the ability to perform multiple integrative activities, even non-agricultural; e) the possibility of offering services to the city functions as recreation and ecological regeneration; f) the sensitivity to the distribution of public funds.

With these assumptions innovative policies can be put in place for the protection and development of the territory, where in particular the rural areas better preserved should be taken into account rather than those compromised and the areas with a widespread presence of farms with high level of vitality rather than those with a prevalence of farms without autonomous capacity. Thus realizing integrated and efficient systems which ensure, with their own resources, permanence and development in the near and long term future. So configuring an active integrated protection of which the defensive actions of territorial planning will only become a prerequisite.

In this view, resilience is configured as a criterion of judgment and operating especially useful in areas where there are competitive factors and criticality. The rural development measures will act more effective if aimed at increasing resilience in a territorial sense.

\section{Bibliography}

Ambrosio-Albalá M., Bastiaensen J. 2010. The new territorial paradigm of rural development: Theoretical foundations from systems and institutional theory, Discussion Paper/2010.02. pp. 1-68. http://www.ua.ac.be/objs/00251118.pdf.

Arzeni A., Sotte F. 2013. Imprese e non imprese nell'agricoltura italiana. Una analisi sui dati del Censimento dell'Agricoltura 2010, Working paper Gruppo 2013, n.20, marzo 2013. www.gruppo2013.it

Brugnoli A. 1990. Valutazione dell'impatto urbano sulla struttura produttiva agricola, Genio Rurale. 4: 52-64.

Brugnoli A., Zappavigna P. 1991. Strutture agricole e sistemi urbani: indagine su aree periurbane del parmense, in Maggioli U. (a cura di), Trasformazioni d'uso del suolo agricolo, Milano, Franco Angeli. pp.173-226.

Ministero delle politiche Agricole Alimentari e Forestali (Mipaaf). 2010. PSN 2007-13 Piano strategico nazionale per lo sviluppo rurale, testo approvato dalla Conferenza Stato-Regioni del 2 ottobre 2010 
http://www.regione.toscana.it.

Pascucci S. 2008. Agricoltura periurbana e strategie di sviluppo rurale: una riflessione, in QA Rivista dell'Associazione Rossi-Doria. 2.

Quaranta G., Salvia R., (2012) Resilienza e politiche di sviluppo nei sistemi socio-ecologici rurali, Territori, anno III, giugno 2012: 2-8.

Torquati B., Giacchè G., Musotti F., Taglioni C. 2009. Agricoltura periur- bana tra adattamento aziendale, funzioni riconosciute e funzioni percepite, Rivista di Economia Agraria, a. LXIV, 3-4: 401- 441.

B. Walker, C. S. Holling, S. R. Carpenter, A. Kinzig. 2004. Resilience, Adaptability and Transformability in Social-ecological Systems, Ecology and Society 9 (2). 5:1-9. http://www.ecologyandsociety.org/ vol.9/iss2/art5/ 